\title{
HABERMAS: A POSSIBILIDADE DA SOLIDARIEDADE ATRAVÉS DA JUSTIÇA
}

\author{
Aylton Barbieri Durão \\ Universidade Federal de Santa Catarina
}

\begin{abstract}
Along the history of politic philosophy there is a hesitation between the ideals of justice and those of solidarity, expressed mostly in the polemics between liberalism and republicanism, since, despite the many versions of both theories, the former proposes a model of judicial reparation of individual rights of the rational selfish ones threatened by the State, while the latter demands a politics of identity acknowledgement by means of collective rights. However, Habermas, through a criticism of the most recent conceptions of both theories, Rawls' liberalism and Taylor's communalism, understands that the discourse theory overcomes such hesitation, showing that it is possible to have solidarity through justice, as modern, pluralistic, multicultural, and complex societies can still allow for a constitutional patriotism around the principles of the Rule of Law, resulting from the political participation of those affected by the norm effect, capable of generating a solidarity between strangers.
\end{abstract}

Keywords: Justice, solidarity, democracy, liberalism, republicanism, discourse.

Resumo: Ao longo da história da filosofia política existe uma aporia entre os ideais de justiça e de solidariedade expressa principalmente na polêmica entre liberalismo e republicanismo, já que, apesar das muitas versões de ambas as teorias, o primeiro propõe 0 modelo da reparação judicial dos direitos individuais dos egoístas racionais ameaçados pelo estado, enquanto o último exige uma política de reconhecimento da identidade mediante direitos coletivos. Habermas, contudo, através de uma crítica das concepções mais recentes de ambas as teorias, o liberalismo de Rawls e o comunitarismo de Taylor, entendem que a teoria do discurso supera esta aporia mostrando que é possível uma solidariedade através da justiça, na medida em que as sociedades modernas, pluralistas, multiculturais e complexas, ainda assim podem permitir um patriotismo constitucional em torno dos princípios do estado de direito resultante da participação política dos próprios afetados pela entrada em vigor da norma, capaz de gerar uma solidariedade entre estranhos.

Palavras-chave: Justiça, solidariedade, democracia, liberalismo, republicanismo, discurso. 
Há uma concepção recorrente ao longo da história da filosofia política segundo a qual as relações sociais são marcadas por uma aporia entre os ideais da justiça e da solidariedade: Aristóteles, em sua reflexão sobre a amizade nos livros VIII e IX da Ética a Nicômaco, começou justamente com a emblemática afirmação de que "os amigos não precisam da justiça para nada, mas os justos ainda assim precisam ter amigos"; esta mesma ideia persiste entre os autores modernos, pois, como recordou Taylor, Hume também observou que, quando os indivíduos começam a reivindicar os seus direitos, em uma sociedade até então baseada na solidariedade espontânea e, inclusive, no sacrifício recíproco, destrói-se esta rede de benevolência mútua ${ }^{1}$.

Mas onde o antagonismo entre justiça e solidariedade aparece de forma mais visível é no conflito entre o liberalismo e o republicanismo ${ }^{2}$, tanto na filosofia moderna quanto na contemporânea. O liberalismo concebe o indivíduo como um egoísta racional, por isso, desenvolve um modelo fraco de regulação social, baseado na revisão judicial (judicial review), uma vez que a justiça deve amortecer os inevitáveis conflitos de interesses ou, no caso dos liberais cívicos como Rawls e Dworkin, compensar as desvantagens sociais com políticas de ação afirmativa e até mesmo igualitaristas. O republicanismo (que Habermas não diferencia do comunitarismo), por outro lado, considera que a identidade se forma através de relações de solidariedade e, sobre estes vínculos sociais mais fortes ${ }^{3}$, se assentam a participação política e o civismo dos cidadãos como uma forma de recordar as origens e reafirmar os valores definidores que possibilitam o reconhecimento ético da própria comunidade.

Ao introduzir o sistema jurídico no papel de intermediário entre os sistemas sociais e o mundo da vida como principal responsável pela

\footnotetext{
1 TAYLOR, Ch. Argumentos filosóficos, p. 242. "De acordo com Hume, a justiça é uma virtude importante quando há escassez e as pessoas não se movem espontaneamente por laços de afeto para a benevolência mútua. Quando o primeiro não é o caso, não há razão para dividir equitativamente os recursos; onde o último não ocorre, não há lugar para manter a gente sob uma norma de distribuição. Além do mais, no segundo caso, o fato de se tentar reforçar uma norma romperia muito possivelmente os laços existentes: insistir incisivamente em dividir gastos com um amigo significa que, de algum modo, faltam vínculos de benevolência mútua ou que eles não são adequados. Não há forma mais rápida para se perder amigos. De modo semelhante, insistir em direitos claramente definidos pode criar distância em uma família.

2 Para definir liberalismo e republicanismo utilizou-se a interpretação de Habermas sobre estas concepções, as quais, devido a sua enorme diversidade, constituem cada uma delas uma "grande família".

${ }^{3}$ Ibid., p. 253.
} 
integração social nas sociedades complexas, Habermas pretende justamente superar esta aporia entre justiça e solidariedade e mostrar que é possível uma solidariedade entre estranhos, na medida em que, nas sociedades complexas, o direito pode gerar uma base de motivação, ao mesmo tempo, suficientemente flexível para preservar as liberdades subjetivas de ação dos indivíduos e bastante forte para permitir que a autolegislação empreendida pelos próprios cidadãos possa avaliar racionalmente os valores éticos norteadores tanto dos indivíduos como das coletividades ${ }^{4}$.

Foi a partir de Soberania popular como procedimento, publicado em 1988 e incluído como apêndice a Faticidade e validade, que Habermas abandonou a antiga polêmica entre liberalismo e socialdemocracia, a qual marcou o pensamento político europeu dos séculos XIX e XX, e começou uma nova guinada em sua teoria da comunicação, orientada agora para a polêmica entre liberalismo e republicanismo que dominava, há algumas décadas, o pensamento político na América do Norte. Este artigo investigou o significado da Revolução Francesa e o seu legado que ainda permanecia atual na comemoração de seu bicentenário. Depois de analisar três conseqüências da Revolução Francesa, a modernização capitalista, o desenvolvimento do estado nacional e do nacionalismo, ele observou que a sua herança mais promissora foi o despertar das ideias de direitos humanos e de democracia que inspiram até hoje o estado democrático de direito, compartilhada também com a Revolução Americana, com a diferença de que esta foi o resultado das circunstâncias, enquanto na França havia consciência sobre os rumos dos acontecimentos ${ }^{5}$. A distinção de Rousseau entre bourgeois e citoyen, entre o indivíduo portador de direitos subjetivos que devem ser protegidos especialmente contra as intervenções do estado e o cidadão que delibera em conjunto sobre as leis da república, caracteriza a Revolução. Isto é refletido no próprio título da Declaração dos Direitos do Homem e do Cidadão, que ilustra a tentativa de mediar entre os direitos dos indivíduos, como propunham os liberais, e os direitos de participação política, como apregoavam os republicanos, mas também na Constituição de 1791. Este modelo constitucional influenciou a maioria das declarações de direito e das constituições modernas que também pretendem harmonizar

\footnotetext{
${ }^{4}$ HABERMAS, J. Faktizität und Geltung, p. 57 et seq.

5 Ibid., p. 603.
} 
direitos humanos e soberania popular, apesar do caráter originalmente antagônico destas concepções 6 .

Naturalmente que Habermas interpreta a polêmica entre liberalismo e republicanismo à luz da teoria da ação comunicativa. As sociedades convencionais dispunham de um ethos que oferecia uma unidade aos valores da cultura, a estrutura da personalidade e as instituições da sociedade, os três componentes em que se subdivide o mundo da vida. Contudo, a modernização social implicou a decomposição do ethos, formando o mundo da vida e os sistemas sociais como o mercado e a política. Além disso, a ação comunicativa do mundo da vida também perdeu o caráter unitário que possuía nas sociedades convencionais porque se tornou reflexiva, uma vez que os agentes adquiriram o poder de colocar em discussão os valores de sua própria sociedade, ocasionando a fragmentação do ethos e a conseqüente pluralização das formas de vida e concepções do bem. Habermas afirma que os discursos são formas reflexivas da ação comunicativa que podem gerar consenso, mas também podem gerar dissenso na medida em que permitem aos agentes questionar os valores tradicionais ${ }^{7}$, pois, como reação à decomposição do ethos, surgiu tanto a possibilidade de recusar a forma de vida tradicional quanto de resgatar um conceito de vida boa a partir de razões. Os agentes passaram a poder decidir sobre o próprio conceito do bem e, como conseqüência, se desenvolveu uma ampla literatura sobre o significado de uma biografia vivida conscientemente ${ }^{8}$. Porém, não somente os agentes individuais adquiriram esta liberdade com relação às tradições; os agentes coletivos também adquiriram a capacidade para deliberar sobre o que é vida boa para eles, ocasionando a multiplicação das formas de vida. Esta dimensão ética das concepções do bem, que não pode ser aceita em comum por todos, exige dos agentes que determinem conscientemente as suas vidas pelos padrões de valores próprios, pois a dimensão ética demanda a autorrealização dos agentes por meio dos discursos ético-existenciais ou éticopolíticos?.

Ao se tornar reflexiva, a ação comunicativa possibilitou o individualismo dos projetos pessoais e o pluralismo das formas coletivas de

\footnotetext{
6 Ibid., p. 603.

7 Ibid., p. 56.

$8 \mathrm{Ibid} ., \mathrm{p} .125$.

$9 \mathrm{Ibid} ., \mathrm{p} .125-6$.
} 
vida. Contudo, as normas sociais não podem se reduzir às questões de realização pessoal ou coletiva, porque, com o individualismo e a pluralização das formas de vida, se tornou mais importante o problema da convivência de todos em conjunto na sociedade. Alguns problemas se referem à humanidade como um todo e não somente aos projetos de vida do indivíduo ou do grupo realizados com sucesso; estas questões que podem ser de interesse simétrico de todos pertencem à moral e não à ética. Mas a moral também se tornou reflexiva e necessitou ser avaliada em discursos morais que averiguam o que é realmente do interesse simétrico de todos os envolvidos ${ }^{10}$. Ao contrário dos discursos éticos, os discursos morais têm que se desprender de todo egocentrismo ou etnocentrismo, pois somente são legítimas as normas que podem ter o assentimento de todos os implicados. Isto se manifestou na literatura filosófica moderna em teorias que fundamentam a validade das normas em princípios, como o imperativo categórico kantiano e o princípio da felicidade dos utilitaristas, ou em procedimentos, como o mecanismo de representação de Rawls ou a própria ética discursiva. A moral considera o ponto de vista da autonomia ou da autodeterminação de todos os seres humanos que obedecem racionalmente regras depois da discussão sobre a sua universalização, e não somente do sujeito ou do coletivo.

Habermas pensa que o debate atual nos Estados Unidos entre liberais e republicanos se apropriou desta decomposição do ethos anteriormente ancorado no substrato religioso ou metafísico, gerando a distinção entre questões éticas e morais. Para explicá-lo, ele se baseia no estudo de Frank Michelmann sobre a tradição constitucional norte-americana. Michelmann observou que o constitucionalismo americano, como se manifesta na prática profissional do Judiciário e do Legislativo, bem como na opinião pública americana, está baseado em premissas que consideram a Constituição segundo duas perspectivas: em primeiro lugar, o direito provém da vontade soberana do povo que decide sobre si mesmo; em segundo lugar, o direito é o resultado do império impessoal das leis e não da vontade dos homens. Contudo, estas premissas vêm de tradições filosóficas diferentes e antagônicas entre si, mas Michelmann crê que não seja possível suprimir nenhuma das duas vertentes, o que tem como consequência a permanência indefinida das controvérsias $^{11}$. Esta interpretação concorda com a concepção exposta em

10 Ibid., p. 126-7.

11 Ibid., p. 129. 
Soberania popular como procedimento na medida em que Habermas considerava que tanto a Revolução Francesa como a Revolução Americana expuseram, sem chegar a uma síntese, a tensão entre democracia e direitos humanos, incorporando perspectivas enfrentadas em suas respectivas legislações.

A pesar de que os pares de conceitos moral e ética, direitos humanos e soberania popular não possam ser relacionados entre si estritamente, no caso do debate norte-americano atual entre liberalismo e republicanismo pode-se dizer que o liberalismo conecta a moral com os direitos humanos, enquanto o republicanismo associa a ética com a soberania popular. Isso ocorre porque os liberais pretendem encontrar uma fundamentação para os direitos do homem por meio da restauração dos conceitos liberais clássicos de estado de natureza e contrato social, submetidos a determinadas condições que garantem a moralidade do procedimento. Os republicanos, por outro lado, ancoram a soberania popular em uma forma de vida específica ou uma eticidade capaz de permitir o desenvolvimento da democracia ${ }^{12}$. Portanto, no debate atual, se reproduz a perspectiva de competição e confrontação entre direitos humanos e soberania popular que marca a historia da filosofia política e jurídica depois de Renascimento.

Se a filosofia política e jurídica contemporânea, ao menos desde as Revoluções Francesa e Americana, no final do século XVIII, está cindida entre liberalismo e republicanismo, não há dúvida de que esta questão ganhou novo interesse com a discussão em torno dos princípios do estado democrático de direito nos Estados Unidos. A publicação de Uma teoria da justiça (1971) de Rawls iniciou um debate sobre os fundamentos da concepção política da justiça de caráter universalista e liberal que resgata as ideias de neutralidade do estado com relação à concepção do bem dos cidadãos; contudo, como reação contextualista ao liberalismo de Rawls, o livro de Michael Sandel, Liberalismo e os limites da justiça (1982), recupera as ideias humanistas, republicanas e comunitaristas contra o sujeito isolado do liberalismo ${ }^{13}$.

12 Ibid., p. 129. "As tradições políticas, que eu, em consonância com a discussão realizada hoje nos USA denominarei simplificadamente "liberal" e "republicana" definem, por um lado, os direitos do homem como expressão da autodeterminação moral e, por outro, a soberania popular como expressão da autorrealização ética".

${ }^{13}$ TAYLOR, Ch. Argumentos filosóficos, p. 240-1. 
No capítulo 2 de Faticidade e validade, intitulado "Concepções sociológicas do direito e concepções filosóficas da justiça”, Habermas compara a ausência de qualquer perspectiva normativa no direito desenvolvido pela teoria sistêmica da sociologia do direito de Luhmann com as concepções liberais de justiça de Rawls e Dworkin, que pretendem investigar o ponto de vista normativo da justiça, deixando de lado a base social do direito. O liberalismo de Rawls enfoca a justiça exclusivamente no âmbito do direito, porém se esquece que o direito é um sistema social e, portanto, mantém uma tensão externa com os demais sistemas, especialmente com o mercado e a política ${ }^{14}$. Dworkin tenta, com seu enfoque hermenêutico dos princípios liberais, resolver o problema da neutralidade do estado de direito que surge da teoria da justiça de Rawls; contudo, uma preocupação liberal pelas concepções do bem, além de não ser capaz de convencer os comunitaristas que continuam insistindo em que a política deve exigir mais que do somente a solidariedade com os valores políticos da comunidade, não convence sobretudo à sociologia do direito, particularmente a funcionalista ${ }^{15}$. Habermas afirma que uma concepção da justiça tem que levar em consideração o material mais duro formado pelas instituições da sociedade complexa e não somente a possibilidade de uma eticidade preocupada com a reparação judicial ${ }^{16}$.

Porém, é depois da publicação de Faticidade e validade em 1992, e de Liberalismo político, de Rawls, em 1993, quando se produz a parte mais interessante da polêmica entre eles. Os argumentos de Habermas sobre este debate foram recolhidos em $A$ inclusão do outro, especialmente na segunda parte do livro que se denomina "Liberalismo político: uma polêmica com John Rawls", o qual consta de dois capítulos: o capítulo 2, "Reconciliação mediante o uso público da razão" e o capítulo 3, "Razoável versus verdadeiro, ou a moral das concepções de mundo”.

Em "Reconciliação mediante o uso público da razão", Habermas se concentra em três aspectos da construção da teoria da justiça como equidade de Rawls: em primeiro lugar, considera o desenho da posição original, comparando-a com o modelo discursivo de procedimento; depois Habermas investiga o problema da estabilidade de uma concepção política da justiça

\footnotetext{
${ }^{14}$ HABERMAS, J. Faktizität und Geltung, p. 88.

$15 \mathrm{Ibid}$., p. 86-8.

${ }^{16}$ Ibid., p. 87-8.
} 
com base no equilíbrio reflexivo ou no consenso por superposição; por fim, analisa a relação entre a autonomia dos sujeitos privados em contraposição à autonomia dos cidadãos e conclui que a forma em que se imaginou o procedimento e a solução dos problemas de estabilidade em uma sociedade democrática implica a desvalorização do papel do cidadão e o privilégio dos direitos subjetivos enquanto liberdades básicas.

No que se refere ao desenho da posição original de Rawls, Habermas apresenta também três críticas, todas elas questionam a inadequação do modelo procedimental adotado. Em Uma teoria da justiça, Rawls aceita o ponto de vista do egoísmo racional por razões de argumentação: como considera que o utilitarismo é a teoria moral dominante nos Estados Unidos, então, parte do próprio conceito de egoísmo racional de seu adversário com a intenção de mostrar que, inclusive egoístas racionais, os quais agem somente por autointeresse, ainda assim seriam obrigados a aceitar princípios de justiça. O procedimento desenvolvido por Rawls consiste em encontrar um mecanismo de representação onde as partes, que não são os próprios cidadãos, mas seus representantes, apenas agem racionalmente com base na escolha racional de fins a partir dos meios disponíveis. O mecanismo de representação põe as partes na posição original, onde não há ainda sociedade concreta, e elas estão submetidas ao véu da ignorância, desconhecendo a condição social, econômica, racial, sexual, etc., sob a qual viverão quando o véu da ignorância for gradualmente levantado e aparecerem as instituições reais. Embora os cidadãos, segundo Rawls, não sejam somente racionais, mas também razoáveis, porque podem agir com base em princípios de justiça e reconhecer as cargas de juízo, as partes têm que escolher, por si mesmas, os princípios de justiça e isso apenas a partir do egoísmo racional. O que garante que o resultado da deliberação dos egoístas racionais tenha um sentido moral são as condições do próprio procedimento, a posição original e o véu da ignorância.

O procedimento de Rawls está a meio caminho entre o contratualismo de Hobbes e o de Kant ${ }^{17}$. Os egoístas racionais submetidos às condições do procedimento têm que decidir que princípios seriam os mais vantajosos para si mesmos na futura sociedade, porém, como as partes ignoram as condições reais desta sociedade e sua situação particular nela, terminam por adotar uma posição maximin, o máximo de benefício para os

${ }^{17}$ HABERMAS, J. Die Einbeziehung des Anderen, p. 101 et seq. 
menos favorecidos, porque se lhes couber uma posição de desvantagem, preferem que seja a menos desfavorável possível. Estas condições são expressas pelos dois princípios da justiça. $\mathrm{O}$ primeiro afirma que as estruturas políticas devem garantir o máximo de liberdade subjetiva de ação para os indivíduos; o segundo tem duas partes: (a) considera que todos devem ter os mesmos direitos e oportunidades de acesso aos cargos e (b) que somente podem aceitar as desigualdades que redundem em benefício dos menos favorecidos ${ }^{18}$.

Habermas entende que este mecanismo de representação implica que os egoístas racionais podem deduzir princípios de justiça, porém, como agem apenas segundo o autointeresse, não são capazes de reconhecê-los como princípios de justiça; do ponto de vista das partes, os princípios de justiça foram objeto de uma escolha racional na qual expressaram as suas preferências ${ }^{19}$. Evidentemente que Rawls pode mudar o desenho da posição original e, portanto, as condições procedimentais de seu mecanismo de representação de modo que inclua a possibilidade de que as partes adotem alguma semelhança, ainda que artificial, com as pessoas morais, aproximando-as assim dos indivíduos reais. Porém, isso implicaria a perda das características da proposta inicial ${ }^{20}$.

Como consequência, as partes, na posição original, movidas pelo autointeresse, somente podem compreender o significado dos princípios de justiça como bens e não como direitos já que as partes autointeressadas não têm um verdadeiro sentido moral, pois a moralidade do resultado foi imposta de fora pelas condições do procedimento para agentes que não dispõem de uma estrutura de pessoalidade capaz de compreender o significado de "dever"; eles só podem concluir o que preferem individualmente como bom segundo uma escolha racional. Contudo, há uma notável diferença entre bens e direitos, porque os direitos têm um caráter deontológico que lhes permite ser legítimos, inclusive quando não são adotados efetivamente em lugar nenhum por ninguém, enquanto os bens têm que ser realmente adotados por alguém para que possam valer ${ }^{21}$. Habermas retoma aqui a polêmica de Hart com Rawls sobre a prioridade do primeiro

\footnotetext{
${ }^{18}$ RAWLS, J. Political liberalism, p. 5-6.

${ }^{19}$ HABERMAS, J. Die Einbeziehung des Anderen, p. 70.

20 Ibid., p. 70

${ }^{21}$ Ibid., p. 71-2.
} 
princípio de justiça com relação ao segundo. Hart, cujo conceito de direito está baseado na filosofia analítica da linguagem ordinária, sabe que não se pode estabelecer uma hierarquização absoluta dos bens, porque estes valem enquanto são efetivamente adotados, o que implica que o critério para seguir bens demanda uma gramática diferente daquela dos direitos, pois a hierarquia tem que ser estabelecida empiricamente com base em preferências e não deontologicamente a partir de razões; contudo, o empenho de Rawls em mostrar a prioridade do primeiro princípio de justiça sobre o segundo demonstra que ele atribui um caráter deontológico aos princípios de justiça, mas isso só é possível se forem entendidos como direitos, o problema é que as partes, movidas pela escolha racional acerca de suas preferências só podem compreendê-los como bens ${ }^{22}$.

Por último, Habermas mostra que o desenho do mecanismo de representação de Rawls implica uma carga desnecessária para o próprio filósofo, porque é ele quem tem que estabelecer as condições restritivas que garantem a moralidade exterior das partes. Porém, neste caso, o filósofo tem que conhecer inclusive as condições futuras da sociedade bem ordenada, para impor de saída as regras que obrigariam os egoístas racionais. Mas uma compreensão correta do procedimento poderia deixar para os próprios implicados a tarefa de encontrar os princípios de justiça. $\mathrm{O}$ procedimento discursivo imaginado por Habermas tão somente estabelece as condições para a argumentação dos próprios afetados, porém não pressupõe de antemão as condições às quais eles têm que se submeter para chegar a princípios morais ou jurídicos ${ }^{23}$.

Em Uma teoria da justiça que Rawls está preocupado com os problemas de estabilidade da sua concepção política da justiça. Rawls imagina que os princípios de justiça deduzidos pelo mecanismo de representação têm que ser submetidos aos implicados para verificar se podem ou não ser aprovados com boas razões e alcançar um equilíbrio reflexivo. Este equilíbrio reflexivo se aproveita do desenvolvimento de uma cultura democrática parcialmente sedimentada nas instituições atuais, pelo menos nos Estados Unidos, depois de mais dois séculos ininterruptos de democracia e história constitucional.

22 Ibid., p. 73-4.

23 Ibid., p. 76. 
Posteriormente, ao longo da década de 80, Rawls introduziu algumas modificações em sua concepção inicial, as quais foram expostas mais tarde em Liberalismo político porque ele próprio considerou que a teoria da justiça como equidade incorporou a tradição contratualista moderna como parte da filosofia moral, não distinguiu entre uma doutrina moral e uma meramente política e não refletiu sobre a diferença entre doutrinas compreensivas e as que se mantêm exclusivamente no campo político ${ }^{24}$. Agora ele ficou mais preocupado em lavar a sério o fato do pluralismo e isto exigiu inumeráveis mudanças na terceira parte da teoria, relativa aos problemas de estabilidade ${ }^{25}$, pois, dadas as condições das sociedades democráticas, o pluralismo das visões de mundo, longe de possibilitar que se chegue a um consenso final, tende a um crescimento continuo e, por isso, a unanimidade somente pode ser alcançada com o preço da democracia ${ }^{26}$. Por conseguinte, ele desenvolveu apenas uma concepção política da justiça, a qual não é geral, já que só envolve questões de política e deixa todas as demais como estão, e, também não é compreensiva, porque não defende um conceito do bem ou pretende competir com as doutrinas compreensivas sobre a verdade da própria teoria. A justiça como equidade só aspira gerar um consenso por superposição entre as várias doutrinas compreensivas razoáveis, que são aquelas que são capazes de aceitar princípios de justiça e suportar as cargas do juízo. Segundo Habermas, o modelo inicial em dois níveis da teoria da justiça, que separava questões de fundamentação procedimental dos princípios de justiça e questões de estabilidade da teoria por meio do equilíbrio reflexivo foi invertido e as questões de estabilidade se confundiram com as próprias questões de fundamentação.

Habermas considera que, com a finalidade de explicar o sentido de "político" em oposição a "metafísico", a nova versão da teoria proposta por Rawls abandona a preocupação pela verdade, substituindo-a pela estabilidade $^{27}$. O liberalismo político não pretende ser uma concepção verdadeira, mas tão somente razoável. Isso significa que o liberalismo político deve explicar como as várias doutrinas compreensivas razoáveis podem chegar a um consenso superposto no qual elas, a partir sua própria

\footnotetext{
${ }^{24}$ RAWLS, J. Political liberalism, p. xvii.

25 Ibid., p. xiv.

${ }^{26} \mathrm{Ibid}$., p. xviii-xix.

${ }^{27}$ HABERMAS, J. Die Einbeziehung des Anderen, p. 81-2.
} 
concepção do bem, consideram aceitáveis os princípios de justiça. A concepção política é razoável se as doutrinas compreensivas razoáveis puderem dar o seu consentimento aos princípios de justiça e a determinadas essências constitucionais que representam uma agenda política mínima; a verdade dos princípios somente pode ser afirmada dentro de cada uma das doutrinas razoáveis, porém não do ponto de vista da própria teoria.

Contudo, Rawls pretende que a sua teoria seja mais do que um modus vivendi, na medida em que os cidadãos possam aceitar o consenso superposto e os princípios de justiça com boas razões e não somente como parte de um processo de tolerância mútua por causa do inevitável pluralismo das concepções de vida. Manter-se dentro dos limites da política evita que a concepção política da justiça tenha que competir com as outras doutrinas, permitindo alcançar o consenso por superposição

Porém, Habermas indaga se justamente o fato de que as teorias morais e políticas, desde o Renascimento, reclamarem para si o reconhecimento de sua verdade não foi um fator que conduziu à tolerância como solução para um conflito que não poderia ser resolvido simplesmente pela violência ${ }^{28}$.

Finalmente, Habermas recorda que o liberalismo, inclusive o liberalismo político, implica a preponderância das liberdades subjetivas de ação sobre a soberania popular e, por conseguinte, a concepção política da justiça reduz o papel da cidadania em favor das liberdades individuais. Os liberais insistem na liberdade dos modernos, caracterizada pela proteção da vida, a liberdade de consciência, de expressão e de crença, bem como o direito à propriedade, que constituem o núcleo do direito subjetivo e privado. Os republicanos defendem a liberdade dos antigos, ou seja, os direitos de participação política que possibilitam a autodeterminação dos cidadãos. Rousseau e Kant tentaram deduzir os direitos subjetivos dos indivíduos e os direitos de participação e comunicação dos cidadãos da mesma fonte, na autonomia moral e política, pois os direitos liberais básicos não podiam constituir uma limitação da autodeterminação dos cidadãos, nem ser instrumentalizados por ela ${ }^{29}$. Rawls parte da mesma ideia, porém, justamente por causa do desenvolvimento da concepção política da justiça em duas etapas, o modelo da teoria da justiça tem como consequência a prioridade das liberdades básicas que formam a autonomia do indivíduo

\footnotetext{
${ }^{28}$ Ibid., p. 87.

29 Ibid., p. 89.
} 
sobre a autonomia do conjunto dos cidadãos, e isso apesar das intenções de Rawls de incorporar os cidadãos nas diversas fases de justificação dos princípios de justiça ${ }^{30}$. Pois, em primeiro lugar, os egoístas racionais deduzem os princípios de justiça através do mecanismo de representação e só depois o véu da ignorância é gradualmente retirado na medida em que são introduzidas as instituições reais da sociedade. No primeiro nível, não se pode falar de democracia, porque esta tem apenas existência virtual, dado que não passa de um procedimento imaginado para deduzir os princípios de justiça; porém, no segundo nível também não, pois, à medida que se suprime o véu da ignorância, os cidadãos encontram os princípios de justiça já constituídos às suas costas. A única coisa que resta para os cidadãos é discutir sobre a estabilidade política da concepção política da justiça e isso a partir de suas próprias concepções do bem, sem precisar levar em consideração a própria concepção política da justiça ${ }^{31}$.

Além do mais, para alcançar o consenso superposto, a concepção política da justiça considera que os cidadãos devem discutir apenas sobre a estabilidade de um conjunto mínimo de questões políticas, como são os princípios de justiça e as questões de justiça básica. Rawls denomina "razão pública” à discussão dos cidadãos sobre esses elementos mínimos da política. O resto pertence à razão não-pública, que não é igual à privada, porque constitui a esfera social onde as pessoas se encontram para interagir coletivamente, como nos clubes ou nas igrejas, mas também não é pública, porque representam instituições que fomentam valores que não são compartilhados por todos ou diz respeito à própria razão privada. Por conseguinte, os cidadãos são obrigados a aceitar princípios fundados fora do jogo democrático, portanto, a soberania popular é limitada pelos princípios de justiça e pelas essências constitucionais fundamentados moralmente pelo procedimento.

Depois da polêmica em torno dos limites do liberalismo de Rawls, Habermas começa, na parte 3 de $A$ inclusão do outro, intitulada "Tem futuro o estado nacional", uma discussão sobre a aparição, desenvolvimento e futuro do estado nacional diretamente envolvida com o republicanismo.

\footnotetext{
30 Ibid., p. 89.

31 Ibid., p. 89-90. "Os cidadãos... não podem atiçar o flamante núcleo radical democrático da posição original na vida real de sua sociedade, porque a partir de sua perspectiva todos os discursos de legitimação essenciais ocorreriam já no interior da teoria; e os resultados dos debates teóricos se encontram preparados para se sedimentar na constituição."
} 
Habermas está preocupado com a possibilidade de um modelo de integração social diferente daquele do estado nacional, que se tornou dominante nos últimos dois séculos, pois, ao que parece, foi o único com fôlego para resistir às condições da modernidade. Contudo, resgatando a questão kantiana do cosmopolitismo, ele afirma que o estado nacional não pode dar conta dos problemas que surgem no âmbito planetário, os quais provocaram a perda da soberania dos estados nacionais e levaram à formação de organismos pósnacionais ${ }^{32}$.

Habermas considera que o estado nacional moderno surgiu da Revolução Francesa e da Revolução Americana, com características diferentes ao estado de direito dos séculos XVI e XVII. O estado de direito do inicio da Modernidade aparecia para os teóricos do contrato social, por exemplo, em Hobbes e Locke, como produção consciente de egoístas racionais que escolhiam sair do estado de natureza em busca da segurança do estado civil. O estado de direito tinha que suportar toda a carga da integração social de uma sociedade baseada no modelo antropológico do atomismo social. Como reação ao liberalismo do período anterior, a finais do século XVIII e a princípios de XIX, o estado nacional possibilitou ancorar o estado, definido como organização política e jurídica, no conceito de nação ou povo. A nação tem originalmente um sentido não político, pois se refere à unidade de todos aqueles que falam a mesma língua, sustenha uma etnia e costumes em comum. A fusão do estado de direito e da nação possibilitou uma solidariedade entre os membros do povo; afinal, havia muitos laços entre os membros de um estado nacional e todos compartilhavam um mesmo destino; assim se oferecia uma alternativa sacra para a integração social. Além do mais, o estado nacional, justamente porque dependia desta nova forma de solidariedade, trouxe consigo a necessidade da participação política dos cidadãos. Consequentemente, o estado nacional resolveu dois problemas ao mesmo tempo, gerou um modo de integração social, pois permitiu um vínculo entre os membros do povo, e introduziu uma forma de legitimação fundada na participação democrática dos cidadãos ${ }^{33}$. Esta particular simbiose entre republicanismo e nacionalismo resultou da construção artificial de escritores, intelectuais e literatos, especialmente ligados ao romantismo, que desenvolveram o conceito de unidade do povo como fonte de participação

32 Ibid., p. 145.

33 Ibid., p. 135-6. 
política $^{34}$. O caráter artificial do estado nacional fica claro quando se recorda que os estados positivos já existiam, pelo menos na França, Inglaterra, Portugal e Espanha, desde o Renascimento, e, embora não se possa sustentar as concepções contratualistas sobre a constituição dos estados mediante um pacto social consciente entre os cidadãos, pois os estados modernos têm uma origem histórica e contingente, não resta dúvida de que é a existência da instituição estatal que define as suas dimensões territoriais e, conseqüentemente, a população dos próprios estados, pois, muito da unidade étnica, lingüística e cultural dos estados modernos foi conseguida a partir da repressão e da expulsão de minorias, como os judeus, ainda que a unificação tardia na Alemanha se deva, em grande medida, ao movimento romântico, ao nacionalismo e à mobilização política do povo como uma unidade orgânica resultante da conexão entre nacionalismo e republicanismo.

$\mathrm{O}$ estado nacional reage, portanto, aos problemas de legitimidade e integração social surgidos por causa da modernização social, pois com a formação dos sistemas sociais se esfumou a capacidade de vinculação dos agentes proveniente da solidariedade do mundo da vida. A modernização social se revelou, por exemplo, na perda da unidade religiosa da Idade Media e na pluralização de convicções que arruinou a antiga fundamentação do poder político na autoridade de Deus ou da Igreja. Além disso, o próprio desenvolvimento da economia capitalista implicou a ampliação das formas de ação baseadas no cálculo de benefícios, pondo em perigo o entendimento da ação comunicativa ${ }^{35}$. O nacionalismo, forjado pelo romantismo, permitiu substituir a solidariedade do mundo da vida pela solidariedade do povo que tem uma origem e um destino comuns.

A simbiose entre nacionalismo e republicanismo tornou possível preencher algumas lacunas no estado positivo, porém, o estado nacional, com sua vinculação entre nação e cidadania, logo revelou que existe uma tensão entre o nacionalismo e o republicanismo: em primeiro lugar, o estado positivo não tem como justificar as fronteiras territoriais e a limitação da população, porque isso não depende de razões, mas da circunstância histórica; ainda que o recurso à ideia de nação pudesse legitimar as fronteiras estatais como fronteiras nacionais ${ }^{36}$, se multiplicaram os conflitos entre

\footnotetext{
34 Ibid., p. 136-7.

$35 \mathrm{Ibid} ., \mathrm{p} .135$.

36 Ibid., p. 140.
} 
estados para reunir cada povo em um mesmo estado e conseguir um estado para cada povo; em segundo lugar, a manipulação política do nacionalismo desembocou em incansáveis conflitos nos últimos dois séculos, sobretudo porque serve como desculpa para transformar os problemas internos ao estado, como a luta de classes, em conflitos externos ${ }^{37}$.

A partir desta origem comum, nos séculos XVIII e XIX, caracterizada pela conexão entre a participação cidadã, apregoada pelo republicanismo e o nacionalismo, se desenvolveu tanto o pensamento alemão de Carl Schmitt e o etno-nacionalismo, por um lado, como a moderna perspectiva do comunitarismo na América do Norte, por outro. Carl Schmitt e o etnonacionalismo insistiram na vinculação entre cidadania e povo, o que significa que apenas é possível uma participação ativa em defesa de valores compartilhados em comum. Segundo seu ponto de vista, ainda se pode falar em unidade de costumes nas sociedades atuais, recusando o fato de pluralismo, o que implica o euroceticismo com relação a uma união autenticamente política de múltiplos povos ${ }^{38}$. O comunitarismo de Michael Walzer ou de Charles Taylor, que para Habermas é uma forma de republicanismo, porque resgata a vinculação entre a participação cidadã do republicanismo ou humanismo cívico com a comunidade de valores, é, contudo, mais sensível ao pluralismo.

Charles Taylor questiona a neutralidade liberal com respeito à concepção do bem dos cidadãos. Liberais como Rawls concebem os princípios de justiça a partir do conceito de "dever" como costuma ocorrer com as éticas de origem kantiana e o convertem em um super bem que elimina todos os demais, porém, Taylor recorda que o dever é somente um entre os múltiplos bens da sociedade. Uma ética inarticulada se caracteriza justamente por superpor um bem sobre os demais e convertê-lo em um "hiper-bem”, em um critério para determinar as proposições corretas ${ }^{39}$. O liberalismo sequer é capaz de reconhecer o dever como um bem entre os demais e o toma como o fundamento da perspectiva moral, o qual pretende ser neutro com relação às concepções do bem. Para as éticas inarticuladas, o dever possibilita uma posição neutra, pois deixa intactas as concepções do bem e possibilita que os cidadãos levem em consideração o ponto de vista da

37 Ibid., p. 140-1.

38 Ibid., p. 160-1.

39 TAYLOR, Ch. As fontes do self, p. 118. 
justiça em oposição às concepções éticas relativas à vida boa. Porém, ao escolher o dever como hiper-bem, o liberalismo comete uma versão da contradição pragmática, pois não tem sentido opor o dever aos bens e compreender o dever como separado dos bens. O dever é tão somente um bem que pode ser escolhido nas sociedades modernas como critério para a vida boa, sem que a perspectiva da justiça baseada no dever deixe de ser uma concepção a mais da vida boa ${ }^{40}$.

Por partir da filosofia de Hegel, Taylor pode fundamentar a sua interpretação do comunitarismo em uma teoria da modernidade que reconhece o desenvolvimento da subjetividade e do liberalismo na ética e política contemporâneas. Quer dizer, Taylor não pretende resgatar a concepção da comunidade como uma unidade de costumes, pois, na modernidade, não se pode simplesmente recusar o ponto de vista da neutralidade política defendido pelos liberais. $O$ fato do pluralismo é reconhecido por Taylor, bem como a necessidade de que o estado de direito tenha que garantir uma esfera de liberdades individuais para os cidadãos. Logo, os direitos têm a forma de direitos subjetivos e os indivíduos devem ter acesso a eles através de uma distribuição individual como acontece com os bens econômicos. Contudo, esta é somente uma possibilidade de modelo político, que pode ser a melhor para determinados casos ou países. Evidentemente que não se pode deixar de considerar a igualdade de todos perante a lei que exige a política universalista e igualitária da dignidade dos seres humanos ou dignidade dos cidadãos. Portanto, o reconhecimento da dignidade igualitária demanda um liberalismo que Walzer, no seu comentário sobre Taylor, denomina de "liberalismo 1" e que pode ser o melhor para países de forte imigração como Estados Unidos.

O problema é que isso não é suficiente porque existem demandas culturais feitas pelos cidadãos que não ficam adequadamente representadas pelo modelo do "liberalismo 1" 41. Quando uma determinada comunidade, sexo ou grupo étnico reivindica que se reconheça a peculiaridade de sua forma de vida, os direitos subjetivos feitos sob medida para as liberdades subjetivas, que podem ser distribuídas individualmente da mesma forma que os bens econômicos, não são suficientes. Faz-se necessário outro modelo de

40 Ibid., p. 122. "Os teóricos vêem-se presas de uma estranha contradição pragmática, na qual os próprios bens que os movem, levam-nos a negar ou a desnaturar todos estes bens".

41 WALZER, M.: "Comentario". In: TAYLOR, Ch. El multiculturalismo y "la política de reconocimiento", p. 139. 
direito e de estado democrático de direito diferente do liberalismo 1, que Walzer chama "liberalismo 2". O liberalismo 2 entende que os direitos individuais são inadequados para atender às demandas coletivas quando os cidadãos reclamam o reconhecimento de sua forma de vida e, portanto, a sua própria identidade ${ }^{42}$. A política da dignidade igualitária não pode ser satisfeita somente com base no universalismo do liberalismo 1, porque a dignidade igualitária depende do reconhecimento da cultura do outro como tendo o mesmo valor que a cultura dominante. Deste modo, o liberalismo 2 permite complementar o liberalismo 1 com direitos coletivos que exige uma atuação do estado democrático de direito capaz de garantir as reivindicações culturais dos povos, grupos, sexos ou raças normalmente marginalizadas pela política da igualdade liberal, que é neutro com relação às demandas de reconhecimento. De fato, Walzer considera que o liberalismo 2 é a forma dominante da política em estados-nações como Noruega, França ou Holanda $^{43}$ onde há uma homogeneidade cultural maior do que nos Estados Unidos, o que demanda a proteção pública da cultura nacional. O liberalismo 2 resulta mais sensível às necessidades dos cidadãos, pois permite que se alterne uma política de liberdades individuais com a proteção da cultura coletiva. Por conseguinte, em Quebec, que é uma região especial do Canadá, dado que os cidadãos falam francês e são de maioria católica em oposição ao resto do país de língua inglesa e religião protestante, deve-se fazer uma legislação especial para a proteção das suas particularidades culturais

Taylor e Walzer são conscientes de que isso pode ocasionar um prejuízo às liberdades individuais em determinados casos, pois as minorias podem ver-se obrigadas a conviver com um poder público que favoreça a coletividade dominante, por exemplo, os cidadãos de origem inglesa, que vivem em Quebec, que neste caso constituem uma minoria, teriam que usar o francês, pelo menos em ocasiões oficiais, e conviver com os privilégios públicos para o catolicismo ${ }^{44}$, porém, pensam que este é um fato da política que não há como eliminar, uma vez que sempre se deve escolher entre dois

\footnotetext{
42 Ibid., p. $139-40$.

43 Ibid., p. 141.

${ }^{44}$ TAYLOR, Ch. Argumentos Filosóficos. p. 267. "Uma sociedade como Quebec não pode deixar de se dedicar à defesa e promoção da cultura e língua francesas, inclusive se isto implica alguma restrição nas liberdades individuais".
} 
extremos: o máximo de liberdade individual ou o máximo de defesa dos valores da comunidade ${ }^{45}$.

O liberalismo tentou apresentar, ao longo dos anos 80, uma resposta ao comunitarismo. Rawls aceitou que seu construtivismo kantiano estabelecia condições para o procedimento da posição original submetida ao véu da ignorância que obrigavam às partes a se por no ponto de vista moral, regido pelo dever, que somente considera o aspecto da justiça; portanto, a teoria da justiça era uma doutrina compreensiva, pois possuía um conceito de bem. Para levar a sério o fato do pluralismo, Rawls desenvolveu a concepção política da justiça que pretende tão só um consenso superposto entre distintas doutrinas compreensivas razoáveis. Rawls respondeu ao comunitarismo sustentando seu ponto de vista de que o estado democrático de direito tem que ser neutro com relação às concepções éticas do bem, porém o liberalismo político pode pretender ser aceito pelas concepções do bem como algo mais do que um modus vivendi, como uma forma de vida que obtém estabilidade e consentimento dos cidadãos das sociedades democráticas. Dworkin, que sempre buscou incorporar a perspectiva hermenêutica em sua teoria do direito, a tal ponto que, em lugar de partir da perspectiva normativa do procedimento kantiano, considera os direitos subjetivos como trunfos que devem ser preservados na luta contra fines coletivos, de modo que alguma racionalidade já foi incorporada nas práticas jurídicas e políticas das sociedades democráticas pelas lutas sociais depois de mais de dois séculos de tradição constitucional, pretende mostrar que, nas sociedades modernas, é possível apenas a ideia de comunidade com base em valores políticos ${ }^{46}$. Portanto, o liberalismo reagiu mostrando que os princípios do estado democrático de direito podem constituir uma forma de vida nas sociedades democráticas, a única capaz de encontrar o apoio de todos os cidadãos em condições reais de pluralismo. Portanto, o liberalismo tentou estabelecer a solidariedade através da justiça.

Taylor reconheceu os esforços do liberalismo por superar a perspectiva atomista e encontrar um apoio motivacional nas condições da sociedade democrática, contudo, desconfiou do sucesso desta estratégia, pois

45 WALZER, M. "Comentario". In: TAYLOR, Ch. El multiculturalismo y "la política de reconocimiento". p. 141-2. "Não duvido que haja uma tensão, e às vezes um conflito aberto, entre estes esforços oficiais pela reprodução social e os esforços extra-oficiais das minorias... A tensão e 0 conflito parecem inerentes ao liberalismo 2, mas isto não é razão para recusá-lo..."

${ }^{46}$ DWORKIN, R. La comunidad liberal, p. 176. 
ainda se sentia falta, no liberalismo, da concepção de participação popular do humanismo cívico. O liberalismo pode pretender que os cidadãos sejam motivados pela reparação judicial de seus direitos e pela ideia de justiça, aceitando uma forma de patriotismo que Taylor denomina "patriotismo pelo direito" ${ }^{7}$; porém, neste caso, tem que mostrar como é possível que os cidadãos podem agir em defesa do estado de direito da mesma forma como estão dispostos a lutar pelo reconhecimento; contudo, uma vez que o modelo do patriotismo pelo direito está centrado nos direitos individuais, considera que os cidadãos estão fundamentalmente preocupados por recuperar seus direitos por meio dos tribunais, por assegurar a igualdade de tratamento e por exercer influência política. Os cidadãos vêem a política instrumentalmente como espaço para exercer poder uns sobre os outros e só esperam do estado que leve em conta as suas preferências particulares ${ }^{48}$. Porém, neste caso, a política de reparação judicial esquece o elemento fundamental da tradição republicana: a liberdade exige uma participação cidadã ativa no autogoverno, que é incompatível com a concepção liberal de política como influência recíproca, inclusive quando se introduzem os mecanismos de compensação e reparação através da justiça ${ }^{49}$.

Habermas pretende, com a política deliberativa, aceitar o desafio de explicar a solidariedade através dos princípios do estado democrático de direito. Para ele, o liberalismo não pode cumprir esta tarefa porque parte de um conceito de direito, de política e de cidadania incompatíveis com as exigentes condições de integração social pela justiça. O liberalismo considera os direitos segundo o modelo dos direitos subjetivos ${ }^{50}$. O liberalismo clássico, com Locke, entendeu os direitos como direitos naturais individuais de um suposto estado de natureza e a versão utilitarista posterior seguiu fundando os direitos no egoísmo racional de indivíduos que apenas levam em consideração o seu próprio interesse e não a vontade soberana de povo. Rawls, por outro lado, afirma a prioridade de primeiro princípio de justiça, que define as liberdades subjetivas de ação sobre o segundo princípio, bem como da primeira parte do segundo princípio da igualdade de oportunidades sobre a segunda parte do beneficio aos menos favorecidos. Inclusive a

\footnotetext{
${ }^{47}$ TAYLOR, Ch. Argumentos Filosóficos, p. 259.

$48 \mathrm{Ibid} ., \mathrm{p} .263$.

$49 \mathrm{Ibid}$., p. 263-4.

50 HABERMAS, J. Die Einbeziehung des Anderen, p. 280-1.
} 
tentativa de Dworkin para encontrar uma base ética para a política liberal não fez mais do que salvaguardar as liberdades subjetivas de ação contra um estado que deseja impor uma forma de vida a todos. O privilégio dos direitos subjetivos sobre os objetivos ocorre porque, qualquer que seja a versão do liberalismo que consideremos, ela parte do ponto de vista do egoísmo racional dos indivíduos e não da participação solidária dos cidadãos, o que gera um conceito de política como luta entre interesses conflitivos entre os indivíduos com o estado de direito ${ }^{51}$. Então, a política se revela, para os liberais, unicamente como luta social capaz de gerar apenas tolerância, mas nunca um acordo genuíno. Inclusive o consenso por superposição de Rawls não supera a dimensão da tolerância liberal e não pode ser mais do que um modus vivendi, ao contrário do que ele pensa, pois as doutrinas compreensivas no máximo são capazes de aceitá-lo a partir de seu próprio ponto de vista particular sem que isto gere uma autêntica convicção sobre a validade do próprio consenso. Por fim, o liberalismo implica uma dramática redução do papel da cidadania porque, para o liberalismo clássico e o utilitarismo, o estado deve ser reduzido ao mínimo e a participação política não deve ir mais além da formação de uma opinião pública e da votação eleitoral em partidos estatizados ${ }^{52}$. Também para Rawls, a agenda política pode incluir apenas a razão pública que aborda os princípios de justiça e as essências constitucionais, o que estreita demasiadamente o papel de cidadão, pois todo o resto fica no âmbito da razão privada ou da razão não-pública, até o ponto de que um crítico se refere à teoria política da justiça como teoria política sem política.

Contudo, o republicanismo, sobretudo por causa do estreitamento ético da soberania popular, também não pode dar uma resposta adequada ao problema da integração social nas sociedades modernas. Inclusive as versões de Walzer ou de Taylor, que levam a sério o pluralismo e a modernização social, permanecem ainda prisioneiros de um resíduo substancialista que não se encontra mais disponível nas sociedades modernas.

A complexidade social que Habermas investiga em Teoria da ação comunicativa explicita que as sociedades modernas estão divididas em sistemas com lógicas próprias, os quais não admitem nem a ideia de um povo homogêneo nem as exigentes condições do humanismo cívico para a

51 Ibid., p. 282.

52 Ibid., p. 278-9. 
participação dos cidadãos. O liberalismo parte de um ponto de vista mais realista ao recordar que os cidadãos se encontram envolvidos com sistemas que demandam a liberdade subjetiva de ação e uma preocupação com os interesses privados, enquanto o republicanismo segue insistindo em um modelo de cidadania hiperativa que os cidadãos modernos não parecem estar em condições de atender.

Para responder aos problemas originados pela polêmica entre liberalismo e republicanismo, Habermas aplica a sua teoria do discurso com o propósito de desenvolver um modelo de direito, de sistema jurídico e de estado democrático de direito que seja mais sensível que o liberalismo com relação à luta pelo reconhecimento, porém mais realista que o republicanismo, o etno-nacionalismo e o comunitarismo, acerca do papel da cidadania. A política deliberativa deve exigir dos cidadãos simultaneamente o patriotismo constitucional com respeito aos valores políticos básicos e a inclusão sensível à diferença dos grupos que compõem o conjunto da sociedade.

Embora a política de reconhecimento questione fundamentalmente a repressão dos valores, da identidade e da cultura de grupos minoritários da sociedade e, somente em menor escala, os aspectos sociais e econômicos, contudo, não há dúvida de que o não reconhecimento das particularidades das minorias vem potencializado também por uma desvalorização social e econômica, pois, os grupos marginalizados culturalmente se encontram igualmente afetados econômica e socialmente ${ }^{53}$.

$\mathrm{Na}$ atualidade, Habermas detecta quatro casos mais importantes de luta pelo reconhecimento: o feminismo na relação entre os sexos, a identidade coletiva de minorias étnicas e culturais, o nacionalismo de grupos lingüística e culturalmente homogêneos no interior dos estados nacionais e a afirmação da identidade dos povos do Terceiro Mundo contra o eurocentrismo manifestado em movimentos de libertação contra o seu passado colonial ${ }^{54}$. Todos esses fenômenos exigem a disputa na dupla frente da luta pelo reconhecimento das identidades culturais e da superação de uma desvantagem econômico-social acumulada. Habermas entende que a política de reconhecimento não pode ficar nos estreitos limites da compensação

53 Ibid., p. 246.

${ }^{54} \mathrm{lbid}$., p. 246 et seq. 
econômico-social, tal como o liberalismo e a social-democracia tentaram resolver o problema.

A teoria do discurso demanda que sejam os próprios cidadãos, enquanto afetados pela entrada em vigor da norma, que cheguem a um acordo acerca de sua validade e, segundo Habermas, o feminismo constitui o paradigma da luta pelo reconhecimento ${ }^{55}$, em primeiro lugar, porque $\mathrm{o}$ feminismo recorda as insuficiências tanto do modelo liberal de estado como o fracasso da política do bem-estar social. O liberalismo tentou simplesmente esquecer as diferenças entre os sexos e desenvolveu uma política de igualdade formal perante a lei, que resultou em uma enorme desigualdade material entre homens e mulheres. O estado do bem-estar buscou compensar as desigualdades reais com uma política de assistência social que gerou o paternalismo sobre as mulheres e provocou novas formas de desigualdades implementadas pelas próprias leis, justamente aquelas que deveriam nivelar estas desvantagens, pois a proteção às minorias desprovidas de uma cidadania ativa desemboca em discriminação trabalhista, por exemplo. Em meio aos fracassos de ambos os modelos, o feminismo, com as suas críticas e sugestões, desencadeou um processo de mobilização que demonstrou que, inclusive leis justas, quando não vão acompanhadas da participação efetiva dos interessados, podem gerar efeitos contrários, conduzindo ao paternalismo e a novas desvantagens $s^{56}$, por isso, como resultado da discussão aberta pelo feminismo, poderiam ser modificados os pontos de vista de homens e mulheres acerca da política de igualdade econômica, social e cultural. Habermas percebe, no feminismo, um modelo autenticamente discursivo de política que leva em consideração, da parte dos próprios implicados, as diferenças entre homens e mulheres.

Contudo, a política deliberativa não exige a complementação do conceito de direito, talhado sob medida para os direitos individuais, por direitos coletivos, mas apenas a correta compreensão do direito, do sistema de direitos e do estado democrático de direito ${ }^{57}$. Os liberais consideram os direitos segundo o modelo dos bens econômicos, o que significa que podem ser distribuídos individualmente a cada cidadão. Os comunitaristas, como Walzer ou Taylor, pensam que é necessário complementar este modelo do

\footnotetext{
$55 \mathrm{Ibid} .$, p. 303 et seq.

${ }^{56}$ Ibid., p. 303-4.

57 Ibid., p. 242.
} 
liberalismo 1 com o liberalismo 2, que seja capaz de decidir em que caso os direitos podem ser distribuídos individualmente ou se é necessário uma distribuição coletiva. Portanto, para os liberais, o conceito de direito é compatível com o estado de direito neutro com relação a formas de vida boa $^{58}$, enquanto para os comunitaristas, o estado tem que decidir em que circunstâncias devem ser protegidos os direitos individuais e em que casos deve ser defendida uma forma de vida ou concepção do bem ${ }^{59}$.

Tal como o problema foi apresentado, os direitos individuais e os direitos coletivos de reconhecimento aparecem como concorrentes, pois a escolha entre uma das alternativas tem como resultado a decisão inevitável entre ofender os direitos do indivíduo ou negar o direito de uma cultura a sua forma de vida especial. A escolha da política liberal implica a negação dos direito das minorias de expressar a sua forma de vida, porque a liberdade de expressão resulta na imposição da cultura majoritária, mas, inclusive culturas dominantes, são ameaçadas pela neutralidade do estado de direito. Por outro lado, a política de direitos coletivos pode eliminar a separação entre esfera pública e privada, além de esmagar as liberdades individuais e gerar privilégios para determinados grupos.

Mas Habermas pensa que este conflito surge só porque liberais e comunitaristas não compreendem adequadamente o conceito de direito. Para os liberais, os problemas éticos implicados pela luta pelo reconhecimento são simplesmente deixados de lado pela política, que se limita a tratar dos direitos individuais, enquanto, para os comunitaristas, o direito é sobrecarregado com a exigência de levar em consideração direitos coletivos que devem proteger as concepções do bem e as formas de vida boa. Se os direitos são interpretados segundo a teoria do discurso, então, não é necessário nem excluir o reconhecimento, nem advogar por direitos coletivos. $\mathrm{Na}$ medida em que os próprios cidadãos que são afetados pela entrada em vigor da norma podem apresentar suas razões contra ou a favor dos direitos em questão, eles poderão racionalmente decidir o que é o melhor para cada caso. As questões éticas relativas à forma de vida boa não podem ser afastadas sem mais da política, pois os discursos políticos envolvem os problemas morais que são de interesse simétrico de toda a humanidade, os problemas éticos relativos a uma concepção do bem, os problemas pragmáticos sobre

58 Ibid., p. 240.

59 Ibid., p. 241. 
aspectos técnicos e, por fim, as negociações sob condições eqüitativas. Esta dimensão do direito, muito mais ampla que a da moral, demanda que os discursos jurídicos sejam precedidos por discursos morais, éticos, pragmáticos ou pelas negociações eqüitativas ${ }^{60}$. Os discursos jurídicos resultam de um amálgama de informações provenientes de outros discursos com o fim de adequar as deliberações ao sistema jurídico em conjunto e atender a exigência da segurança jurídica.

Ao considerar que a política deliberativa propõe discursos jurídicos que tomam como base elementos dos discursos éticos, Habermas afirma mais que o liberalismo, porém menos que o comunitarismo ${ }^{61}$. Os problemas éticos não devem ser simplesmente ignorados pelo estado neutro, porém também não são meramente assumidos como quer o comunitarismo, pois os cidadãos devem ter a capacidade de seguir conscientemente as suas concepções do bem e formas de vida boa. O modelo da política deliberativa permite que os cidadãos possam introduzir as questões éticas na política, porém exigem que o façam em discursos de autoesclarecimento em torno de qual concepção do bem que se deve aceitar e avaliar racionalmente se as concepções do bem adotadas até então por tradição podem continuar sendo aceitas, como é natural nas condições modernas do pluralismo.

Esta é a razão pela qual não somente não é necessário complementar os direitos individuais com os direitos coletivos, mas inclusive não é desejável. Os cidadãos têm que continuar desfrutando dos bens jurídicos individualmente e estes têm que permanecer sendo distribuídos como são os bens econômicos, pois, do contrário, os afetados estariam obrigados a seguir uma forma de vida apenas porque o grupo ao qual pertencem sempre a compartilhou. A política de reconhecimento não pode implicar a conservação de um modo de vida contra a vontade dos participantes, como resulta da aplicação de direitos coletivos. Habermas recorda que a política não pode defender as concepções do bem da mesma forma que a ecologia pretende proteger a conservação das espécies naturais. As espécies têm que ser protegidas contra a destruição da natureza que é arbitrariamente realizada pelo homem, porém as formas de vida só devem ser protegidas se os próprios afetados estão dispostos a preservá-las. Neste caso, o discurso ético serve para

${ }^{60}$ Estas últimas não são realizadas em discursos, porém exigem condições de equidade que dependem dos discursos.

61 Ibid., p. 287. 
que os envolvidos possam decidir o que é bom para o próprio indivíduo, para seu grupo ou para o conjunto da sociedade. Porém, nestas circunstâncias, podem decidir também mudar as concepções éticas. $\mathrm{O}$ indivíduo deve ter a liberdade de escolher se deseja ou não permanecer com a concepção de vida boa de seus pais, de sua cultura ou de seu país; bem como todo o grupo que possui uma concepção do bem deve ter o poder de preservá-la ou mudá-la segundo os novos tempos ${ }^{62}$. Habermas observa que, na modernidade, várias formas de vida sucumbiram, enquanto outras apenas sobreviveram a custo de mudanças profundas ${ }^{63}$. Os direitos coletivos propostos pelo liberalismo 2 de Walzer e Taylor trazem, em seu seio, o preço demasiado alto do conservadorismo ecológico das espécies culturais, além de atentar contra as liberdades individuais, as quais representam um ganho indiscutivelmente valioso das sociedades modernas. Habermas crê que o modelo político discursivo tem o mérito de permitir a introdução dos problemas éticos na política sem suprimir as liberdades individuais, pois não exige um novo tipo de direitos coletivos, mas apenas que os próprios afetados possam decidir de que modo desejam seguir as suas concepções do bem $^{64}$.

A conseqüência deste modelo de política deliberativa é que o estado democrático de direito deve aguçar a sua sensibilidade para a diferença. Habermas considera que o problema da negação do reconhecimento não provém tanto da neutralidade ética de estado de direito de cunho liberal, mas exatamente do contrário, da inevitável impregnação ética da comunidade jurídica, como é testemunhado pelo privilégio das igrejas cristãs na Alemanha, apesar da liberdade religiosa ${ }^{65}$. O estado de direito sempre dispõe de uma determinada concepção do bem que se tornou dominante na sociedade, pois todo estado, inclusive o estado onde prevalece a política liberal, tem uma substância normativa ou um ethos. Um estado democrático de direito como Estados Unidos, por exemplo, onde a maioria está disposta a considerar que prevalece uma política liberal, ainda assim possui uma substância ética baseada, evidentemente, na defesa dos direitos individuais e na democracia. Como observa Frank Michelmann, a tradição da política

\footnotetext{
62 Ibid., p. 260-1.

$63 \mathrm{Ibid} ., \mathrm{p} .261$.

64 Ibid., p. 259.

65 Ibid., p. 255.
} 
americana não deixa de representar a preservação de uma forma de comunidade, mas, em lugar de uma cultura concreta, o que se preserva é a defesa da própria cultura política ancorada em dois séculos de democracia. Também Dworkin estaria disposto a aceitar uma comunidade liberal em torno dos valores políticos fundamentais. Habermas, contudo, não consideraria suficiente a "comunidade liberal" de Dworkin, porque, como recordou Taylor, ainda se sente a falta, nesta forma de política, de um papel mais ativo de cidadão, pois os valores políticos não podem ser preservados somente nas disputas eleitorais periódicas por meio de indivíduos que buscam a influência recíproca de partidos estatizados.

Neste ponto, se pode responder à pergunta de Taylor sobre a possibilidade de uma solidariedade pela justiça, a qual foi proposta pelo liberalismo cívico em sua nova versão. Nem o liberalismo político de Rawls, com seu consenso superposto, que pretende ser mais do que um simples modus vivendi, nem a comunidade liberal de Dworkin em torno aos valores políticos fundamentais, podem explicar a solidariedade através da justiça porque esta exige muito mais do cidadão, do direito e da própria política do que qualquer versão do liberalismo pode admitir. Habermas pretende responder afirmativamente a questão de Taylor, superando o modelo liberal e aceitando um conceito de cidadania, de direito e de política mais participativos. Porém, uma autêntica solidariedade através da justiça tem que demandar menos do cidadão e da política do que desejam os republicanos em suas várias formas, porque somente é possível ser solidário, no mundo moderno, mediante o modelo da reparação judicial, se a política desenvolver uma sensibilidade com relação à diferença, que é dificilmente conciliável com o comunitarismo, inclusive nas versões pluralistas de Walzer e Taylor.

Para Habermas, o comunitarismo exige demasiado do cidadão com seu modelo de direitos coletivos. Não se pode obrigar aos cidadãos a prosseguir com as tradições que eles já não estão dispostos a preservar, nem mesmo que as correntes migratórias tenham que se submeter ao privilégio atribuído às concepções do bem de uma determinada região do país e, sobretudo, não se pode exigir dos imigrantes mais do que o respeito pelas leis do país de destino, porém jamais a renúncia de suas formas tradicionais de vida. Um estado democrático de direito apenas pode exigir o patriotismo constitucional de seus cidadãos, na forma de um civismo baseado nos princípios políticos de próprio estado de direito, como afirma Dworkin, porém com uma cidadania efetiva e uma participação política real dos 
afetados, o que Dworkin não considera necessário, sob pena de, como demonstrou o feminismo, converter as políticas de igualdade em paternalismo e exclusão.

O patriotismo constitucional, contudo, é sensível à diferença de um modo que o comunitarismo não pode $\operatorname{ser}^{66}$. A propósito da discussão sobre a autodeterminação nacional, Habermas observa que a política de reconhecimento de grupos étnicos que dispõem de uma língua, cultura e passado em comum não é resolvida simplesmente pela autonomia política da comunidade, porque isso implica tão somente a formação de novas maiorias e, conseqüentemente, novas minorias marginalizadas, que originam o mesmo problema agora dentro das fronteiras do novo estado ${ }^{67}$. Ainda que Quebec não deseje a autodeterminação, mas apenas a defesa ativa da língua francesa e da religião católica ameaçadas pela cultura inglesa e protestante, majoritárias no Canadá, a política de reconhecimento de Taylor, por exemplo, pode conduzir à discriminação das novas minorias de anglofalantes e protestantes em Quebec, o que admite o próprio Taylor. O liberalismo 2 leva inevitavelmente à exclusão quando o que deseja é justamente o reconhecimento. Habermas considera que a teoria do discurso com um patriotismo constitucional sensível à diferença é a única que pode permitir uma verdadeira inclusão do outro.

Contudo, na medida em que o estado democrático de direito, baseado no patriotismo constitucional e na inclusão do outro, constitui a substância ética das sociedades ocidentais modernas, a política deliberativa pode responder melhor do que o liberalismo às críticas comunitaristas sobre a neutralidade do estado, porém traz novas dificuldades no âmbito do multiculturalismo. Para Habermas o estado democrático de direito não pode ser neutro com relação às concepções do bem, não somente porque tem que tratar de questões éticas, mas, sobretudo, porque o modelo de política, de sociedade, e, por conseguinte, de liberdade e democracia estabelecido na modernidade é uma forma particular de vida como qualquer outra ${ }^{68}$. Portanto, o estado democrático de direito é uma forma de vida típica da modernidade ocidental, como se pode recordar a partir das críticas de Taylor à contradição pragmática das éticas inarticuladas que aceitam o dever, porém

\footnotetext{
66 Ibid., p. 263-4.

$67 \mathrm{Ibid}$., p. 173.

68 Ibid., p. 263.
} 
que não o reconhecem como uma concepção do bem entre outras. Habermas admite que o estado democrático de direito surge com a modernização social e constitui uma característica da política moderna em sociedades ocidentais, evitando a contradição pragmática que Taylor encontra no liberalismo e, inclusive, evitando a falácia etnocêntrica de considerar que a forma moderna e ocidental de vida seja uma concepção de vida boa para todos os povos e culturas. Apesar de que o estado democrático de direito não seja neutro, já que é uma forma de vida particular, entendê-lo como uma substância ética pode ser aceito também pelos liberais, reconhecendo-o ou não como uma forma específica de vida. Rawls, por exemplo, admite a necessidade de um substrato social para o liberalismo político por meio do consenso superposto, enquanto Dworkin fala de uma comunidade liberal.

Contudo, o fato de que o estado democrático de direito constitui a base normativa das sociedades modernas traz consigo problemas para os que não podem aceitar, com boas razões, inclusive esta concepção ética de vida boa. Evidentemente que não se pensa aqui naquelas concepções autoritárias que recusam a democracia e a tolerância em torno do pluralismo moderno, mas, na América, é especialmente relevante o problema das comunidades indígenas, as quais, apenas ao preço da aculturação, podem participar da estrutura política do estado democrático de direito. A adoção do modelo habermasiano de política deliberativa, baseado na luta pelo reconhecimento em sociedades complexas, pode ser adequada para o caso das mulheres, das minorias raciais ou dos marginalizados em geral, que já compartem a substância ética democrática das sociedades complexas, porém não é suficientemente sensível à diferença no caso de comunidades que não participam das formas modernas de vida, que desejam ser preservadas e que são dignas de ser preservadas; pois o reconhecimento da identidade dos indígenas não é compatível com a sua participação nos discursos práticos, porque, em tal circunstância, a conservação de sua forma de vida dependeria de uma destas três alternativas, igualmente inaceitáveis: ou a negação da sua forma de vida por meio da participação política ativa e a consequente adoção de um modelo alienígena de política; ou os indígenas teriam que se envolver, como afetados pela política deliberativa, para mostrar que não deveriam participar dela, jogando a escada fora depois de subir; ou, ainda pior, caberia aos cidadãos do estado democrático de direito decidir pelas suas costas sobre a conservação da sua própria cultura. 
Pode-se imaginar uma resposta para este problema a partir da teoria discursiva habermasiana, pois, ao admitir que o estado democrático de direito constitui a substância ética das sociedades modernas, os indígenas, como quaisquer outros cidadãos, devem ter a capacidade para realizar conscientemente seus projetos pessoais e sociais, por meio da participação nos discursos racionais, decidindo seguir ou não a sua forma de vida tradicional. Do ponto de vista da política deliberativa poder-se-ia inclusive objetar como uma exclusão condenar os indígenas a sua forma de vida se eles, ou pelo menos alguns deles, já não querem preservá-la. Contudo, esta resposta ainda esquece um aspecto importante, pois há uma diferença significativa entre o fato de que os indígenas possam decidir, por um lado, a partir de sua própria cultura, seguir ou mudar a sua forma de vida tradicional ou que, por outro lado, tenham que se envolver com o estado democrático de direito para fazer esta escolha, uma vez que teriam que participar de um ethos que não é seu, para poder escolher sobre a sua melhor forma de vida. Ao que parece, a política deliberativa e a inclusão do outro ainda não são suficientemente sensíveis à diferença, pois não oferecem uma solução adequada para aqueles grupos ou etnias que não podem aceitar, com boas razões, a substância ética do estado democrático de direito.

\section{Referências bibliográficas}

ARAUJO, L. "Moral, Direito e Política - Sobre a Teoria do Discurso de Habermas”. In: Manfredo Oliveira; Odilio Aguiar; Luiz Felipe Sahd. (Org.). Filosofia Política Contemporânea. Petrópolis: Vozes, 2003, v. 1, p. 214-235. . "Liberalismo, Identidade e Reconhecimento em Habermas". In:

Veritas, Porto Alegre, v. 52, p. 120-136, 2007.

BAYNES, K. The normative grounds of social criticism. Kant, Rawls and Habermas. Albany: SUNY, 1992.

"Democracy and the Rechtsstaats: Habermas's Faktizität und

Geltung”. In: WHITE, S. Cambridge companion to Habermas. Cambridge: Cambridge Univ. Press, 1995, p. 201-32.

BOHMAN, J. "Complexity, pluralism, and the constitutional state: On Habermas's Faktizität und Geltung”. In: Law and Society Review. /s.1./, 28(4):897-930, 1994.

. Public deliberation. Pluralism, Complexity, and Democracy.

Cambridge, Mass.: MIT, 1996. 
CRONIN, C. P. “Translator's introduction”. In: HABERMAS, J. Justification and application. Remarks on Discourse Ethics. Trad. Ciaran P. Cronin. Cambridge, Mass.; London: MIT, 1993, p. XI-XXXI.

DUTRA, D. V. Razão e consenso em Habermas. Florianópolis: Editora da UFSC, 2005.

DWORKIN, R. "Liberal community”. In: California Law Review, 77 (3): 479504, May, 1989.

FERRAZ, C. A. "Habermas: da análise da Öffentlichkeit ao projeto de uma 'teoria do agir comunicativo"'. In: Trans/Form/Ação, vol.33, n. 2, Marília, 2010. HABERMAS, J. Eine Art Schadensabwicklung. Kleine politische Schriften VI. Frankfurt am Main: Suhrkamp Verlag, 1987.

. Faktizität und Geltung. Beitrage zur Diskurstheorie des Rechts und des demokratischen Rechtsstaats. 4.Aufl. Frankfurt am Main: Suhrkamp Verlag, 1994.

. Theorie des Kommunikativen Handelns. Frankfurt am Main: Suhrkamp Verlag, 1995. 2v.

. Die Einbeziehung des Anderen. Studien zur politischen Theorie.

2.Aufl., Frankfurt am Main: Suhrkamp Verlag, 1997.

JIMÉNEZ REDONDO, M. “Introducción”. In: HABERMAS, J. Facticidad y validez. Trad. Jimenez Redondo. Madrid: Trotta, 1998, p. 9-55.

MAIA, A. C. Jürgen Habermas: filósofo do direito. São Paulo: Renovar, 2008. MILLER, D. y WALZER, M. Pluralismo, justicia e igualdad. Trad. Horacio Pons. México: FCE, 1997.

MOREIRA, L, APEL, Karl-Otto, OLIVEIRA, Manfredo. Com Habermas, contra Habermas. São Paulo: Landy, 2004.

NOBRE, M. "Permanecemos contemporâneos dos jovens hegelianos: Jürgen Habermas e a situação de consciência atual”. In: Olhar - Revista de Artes e Humanidades do CECH/UFScar, São Carlos, v. 4, p. 93-102, 2000.

PINZANI, A. \& DUTRA, D. V. Habermas em discussão. Florianópolis: Néfipo, 2005.

RAWLS, J. Teoría de la justicia. Trad. M González. México: FCE, 1993. . Political liberalism. New York: Columbia Univ. Press, 1996.

REHG, W. "Translator's introduction”. In: Habermas, J. Between facts and norms. Contributions to a discourse theory of law and democracy. Trad. William Rehg. Cambridge, Mass: MIT, 1996, p. IX-XXXVII.

ROUANET, L. P. “Soberania e patriotismo constitucional”. In: Revista jurídica, Campinas, v. 21, n. 2, p. 77-83, 2005. 
SIEBENEICHLER, F. B. "A justiça como inclusão do outro". In: Ethica: Cadernos Acadêmicos, Rio de Janeiro, v. 8, n. 2, 2001.

TAYLOR, C. Argumentos filosóficos. Trad. Fina Birués. Barcelona: Paidós, 1997.

. As fontes do Self. A construção da identidade moderna. Trad. Adail Sobrado \& Dinah Azevedo. São Paulo: Loyola, 1997.

TAYLOR, Ch. et al. El multiculturalismo y "la política del reconocimiento". Trad. Utrilla de Neira. México: FCE, 1993.

VALLESPÍN, F. “Introducción”. In: HABERMAS, J. \& RAWLS, J. Debate sobre el liberalismo político. Trad. Vilar Roca. Introd. Fernando Vallespín. Barcelona: Paidós, 1998, p. 9-37.

VELASCO, J. C. “Introducción”. In: HABERMAS, J. La inclusión del otro. Barcelona: Paidós, 1999, p. 11-22. 